\section{Hamsters and interferon}

SIR - It is a pity that in writing about Hayashibara's successful lawsuit against Roche (Nature 368, 486; 1994) you highlighted the use of hamsters in our production of interferon in a way that may cause misunderstanding.

For the manufacture of interferon, there is, besides the Hayashibara method, an in vitro culturing (tank culture) method in which a huge amount of fetal calf serum is required. In 1992, about 180,000 fetal calves were killed for the manufacture of interferon by this method in Japan alone. About half a million calves are slaughtered worldwide to make bioactive substances in this way. Many experimental animals are used in medical research and in developing drugs and cosmetics. It is unfair to single out Hayashibara for criticism. Moreover, the cartoon that accompanies your news story shows little understanding of the respect and remorse shown towards animals killed for the benefit of humans here in the East.

Takaya Mlyamoto

Hayashibara Biochemical

Laboratories, Inc.,

2-3 Shimoishii 1-chome,

Okayama, 700 Japan

SIR - I was a member of the first Biogen team to produce recombinant human interferons in $E$. coli between 1980 and 1984, and would like to comment on interferon production using lymphoblastoid cells grown in hamsters.

(1) When we started large-scale production, our expression levels were of the order of $1-3 \times 10^{8}$ interferon units per litre of bacterial culture fluid. Current yields are at least a factor of 100 higher than this. According to your recent news item, one hamster can produce $2-4 \times 10^{7}$ units. Even with the low titres we had in 1981, one litre of culture fluid produced more interferon than five of the Hayashibara hamsters. As we were running a 30,000 fermentor on a 24 hour "turn", in one day we could make more human interferon than 150,000 baby hamsters would produce in 3-4 weeks of painful tumour growth.

(2) Purified recombinant interferons are as active in humans at those isolated from tissues.

(3) Proteins isolated from human cancer cell culture have a much higher probability of contamination with mammalian cell components than those from bacteria.

(4) The process is out of date. Similar techniques for the production of monoclonal antibodies in rodents have been superseded by efficient methods to produce antibodies using in vitro hybridoma cell culture or bacteria.

This process would not be allowed in Switzerland or Germany as there are alternatives to the production method ${ }^{1}$. Even if we completely ignore the suffering to the animals and the human workers who must care for them, the Hayashibara process as described would never suffice to produce the interferon used today for treating human patients.

\section{Catherine H. Schein}

Swiss Institute for Alternatives

to Animal Testing (SIAT),

Pfingstweidstr 30 ,

\section{$\mathrm{CH}-8005$ Zurich, Switzerland}

1. Reinhardt, C. A. (ed.) Alternatives to Animal Testing. New ways in the biomedical sciences, trends and progress $(\mathrm{VCH}$ Publishers, Weinheim, Germany, 1994).

\section{Charity work}

SIR - Your leading article "Charitable research" was. not entirely accurate in its description of two underlying events.

First, the Charity Commission's proposals arising from an inquiry precipitated by a pressure group's complaint against two cancer research charities did not depend on the quality or otherwise of the published account of any particular piece of research that the charities had funded. The commission made no judgements of research quality, nor did it have the expertise to do so.

Second, your statement that the published report ${ }^{2,3}$ of a study of complementary medicine "is now acknowledged to have been misleading" suffers from the same deficiency as much of the media comment on this topic: it conflicts with the facts as recorded in the research literature. The report ${ }^{2}$ may well have been misrepresented or misunderstood, but that does not make it misleading. It described a study of survival in breast cancer patients receiving complementary therapy compared with those who did not. The investigators from the Institute of Cancer Research had sought a randomized trial, but the Bristol Cancer Help Centre (which offers complementary therapy and was collaborating in the study) had declined on ethical grounds. The study design was therefore inherently imperfect. It was nevertheless approved for support by the peer-review mechanisms of the two funding charities. The report ${ }^{2}$ commented on the drawbacks of an observational trial and the difficulties of matching patients. It was observed that survival rates (absolute or metastasis-free) of Bristol patients differed from the controls. Possible interpretations for this finding were discussed. The experimental design did not allow a definitive conclusion about causes, the report did not draw one, but subsequent media comment did.

The investigators responded ${ }^{3}$ to subsequent debate ${ }^{4}$ by reanalysing their data.
The difference between the Bristol patients and controls was lessened but remained statistically significant. There was still no evidence for any survival benefit of complementary therapy. The original ${ }^{2}$ qualitative finding was thus confirmed ${ }^{3}$.

The Charity Commission has highlighted the responsibility of research charities for the quality of the research that they fund, and has proposed guidelines. There are two further sets of guidelines that the commission might usefully consider. One would cover the publicity launched by medical research charities for particular outcomes of their research. The other would apply to the claims made by alternative medicine charities when offering their therapies to the public.

\section{Peter Garland}

Institute of Cancer Research,

London SW7 $3 A L$, UK

1. Nature 369, 428 (1994).

2. Begenal, F. S. et al. Lancet II, 606-610 (1990)

3. Chilvers, C. E. D. et al. Lancet II, 1185-1186 (1990)

4. Hayes, R. J., Smith P. G. \& Carpenter. L. Lancet Ii. 1185 (1990).

\section{Is Britain immune?}

SIR - Your discussion of questionable research and scientific practices and analysis of the possible means of redress (Nature 369, 261-262; 1994) is written as though scientific misconduct were limited to the activities of US scientists. Why is discussion limited to foreigners, particularly Americans? The United States is to be congratulated on discussing and attempting to deal with this phenomenon through such bodies as the Office of Research Integrity (ORI). This machinery, for all its faults, does at least represent an acknowledgement that a problem exists and tries to deal with it.

No such machinery, formal or informal, exists in Britain. Yet in more than 30 years of clinical research in the field of Alzheimer's disease I have come across examples of each of the different categories of scientific misconduct you mention. Because of greater financial pressures on British researchers, some types of misconduct may be more frequent than others. For example a referee or member of a grant committee of one organization may be instrumental in delaying or refusing an application, only to submit a similar one elsewhere, or a referee may either delay acceptance of or turn down an application while largely replicating the work it reports and attempting to publish the results first.

Is it not time that the subject was more widely discussed as representing as much of a problem in the United Kingdom as it is elsewhere?

\section{Raymond Levy}

Institute of Psychiatry,

De Crespigny Park,

Denmark Hill, London SE5 8AF, UK 